Jurnal Kesmas Asclepius

Volume 1, Nomor 2, Desember 2019

e-ISSN: 2684-8287

p-ISSN: 2656-8926

DOI: https://doi.org/10.31539/jka.v1i2.582

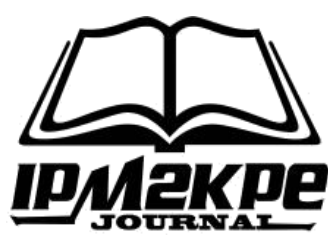

\title{
DUKUNGAN IBU DENGAN KESIAPAN REMAJA PUTRI DALAM MENGHADAPI MENARCHE
}

\author{
Sellia Juwita \\ Universitas Abdurrab \\ sellia.juwita@univrab.ac.id
}

\begin{abstract}
ABSTRAK
Tujuan penelitian ini adalah untuk mengetahui hubungan dukungan ibu dengan kesiapan remaja putri dalam menghadapi menarche. Desain pada penelitian ini adalah kuantitatif analitik. Hasil univariat di ketahui remaja putri yang mendapatkan dukungan ibu sebayak 49,2\% dan yang tidak mendapat dukungan sebanyak 57,8\%, remaja yang siap menghadapi menarche sabanyak $57,4 \%$ dan yang tidak siap sebanyak $42,6 \%$. Hasil analisa bivariate diketahui terdapat hubungan antara dukungan ibu dengan kesiapan remaja dalam menghadapi menarche dimana nilai $p$ value 0,000 . Simpulan, remaja yang mendapatkan dukungan ibu lebih siap menghadapi menarche dibandingkan dengan yang tidak mendapatkan dukungan.
\end{abstract}

Kata Kunci: Dukungan Ibu, Kesiapan, Menarche, Remaja

\section{ABSTRACT}

The purpose of this study was to determine the relationship between maternal support and the readiness of young women in dealing with menarche. The design in this study is quantitative analytic. Univariate results found that young women who received support from mothers were $49.2 \%$ and those who did not get support as much as $57.8 \%$, adolescents who were prepared to face menarche were $57.4 \%$ and those who were not prepared were $42.6 \%$. The results of bivariate analysis found that there is a relationship between maternal support and adolescent readiness in dealing with menarche where the $p$ value is 0,000. Conclusion, adolescents who get maternal support are more prepared to face menarche compared to those who do not get support.

Keywords: Mother Support, Readiness, Menarche, Youth

\section{PENDAHULUAN}

Remaja merupakan masa peralihan dari masa anak-anak ke masa dewasa yang meliputi semua perkembangan yang dialami sebagai persiapan memasuki masa dewasa. Seiring perkembangan biologis, remaja putri akan menjalani suatu fase dimana remaja akan mencapai tahapan kematangan organ-organ seksual yang memiliki kemampuan untuk bereproduksi yang disebut dengan pubertas. Pubertas pada remaja putri dapat ditandai dengan perubahan hormonal yang menyebabkan datangnya menstruasi pertama kali atau yang disebut dengan menarche (Solihah, 2013).

Data yang didapat oleh World Health Organization (WHO) sekitar seperlima dari penduduk dunia dari remaja berumur 10-19 tahun sudah mengalami menstruasi (Effendi \& Makhfudli, 2009). Di Indonesia usia remaja pada waktu menarche bervariasi antara 
10 hingga 16 tahun dan rata-rata menarche pada usia 12 tahun 5 bulan (Munda et al., 2013).

Menurut Santrock (2010) masa remaja berarti tumbuh hingga mencapai kematangan, secara umum berarti proses fisiologis, sosial, dan kematangan yang dimulai dengan perubahan masa pubertas. Remaja didefinisikan sebagai masa peralihan dari masa kanak-kanak ke dewasa dan merupakan tahapan seseorang dimana ia berada diantara fase anak dan dewasa yang ditandai dengan perubahan fisik, perilaku, kognitif, biologis, dan emosi. Kriteria yang paling sering digunakan untuk menentukan masa pubertas adalah munculnya menstruasi pertama (menarche) pada perempuan dan mimpi basah bagi laki-laki (Fajri \& Khairani, 2011).

Ketidakpastian remaja putri dalam menghadapi menarche akan berpengaruh terhadap perilaku remaja putri, karena itu keluarga perlu memberikan dukungan yang baik kepada anak perempuannya karena remaja putri lebih rentan mengalami infeksi saluran reproduksi yang disebabkan iklim Indonesia yang panas dan lembab, bila alat reproduksi lembab dan basah, maka keasaman akan meningkat yang memudahkan pertumbuhan jamur. Penyebab utama penyakit pada saluran reproduksi yaitu imunitas lemah (10\%), perilaku kurang bersih saat menstruasi (30\%), dan lingkungan tidak bersih serta penggunaan pembalut yang kurang sehat saat menstruasi (50\%). Perempuan yang memiliki riwayat infeksi saluran reproduksi mempunyai dampak buruk untuk masa depannya seperti kemandulan, kanker leher rahim dan kehamilan di luar kandungan (Kusmiran, 2012).

Menurut World Health Organization (WHO), remaja merupakan individu yang sedang mengalami masa peralihan yang secara berangsur-angsur mencapai kematangan seksual, mengalami perubahan jiwa anak-anak menjadi dewasa, dan mengalami perubahan keadaan ekonomi dari ketergantungan menjadi relatif mandiri (Notoatmodjo, 2009).

Menarche umumnya terjadi pada usia antara 11-14 tahun. Normal terjadi lebih dini di usia 9 tahun atau lama di usia 15 tahun. Jika anak kita tidak mendapatkan periode menstruasinya di usia 15 tahun, sebaiknya orang tua segera membawa anak ke dokter untuk konsultasi lebih lanjut agar tidak terjadi kelainan pada alat kelamin (Suratmaja, 2013). Menarche adalah hal wajar dan dialami oleh wanita normal. Hal ini semakin parah apabila pengetahuan remaja tentang menstruasi kurang dan pendidikan orang tua yang kurang. Kesiapan mental sangat diperlukan sebelum menarche karena perasaan cemas dan takut akan muncul (Sukarni \& Wahyu, 2013).

Hasil dari penelitian Fajri \& Khairani (2011) menunjukan bahwa terdapat remaja yang mempunyai harapan negatif tentang menarche dan merespon menarche secara negatif. Hal ini dideskripsikan oleh subjek dengan perasaan secara negatif seperti merasa takut, terkejut, sedih, kecewa, malu khawatir dan bingung. Selain itu terdapat $31,2 \%$ responden berada dalam kategori tidak siap menghadapi menstruasi. Trinuryati (2014) dalam penelitiannya menyebutkan terdapat $19,4 \%$ responden tidak siap menghadapi menarche dan 80,6\% siap menghadapi menarche. Lebih lanjut Ramadhaniyati (2014) dalam surveynya di SDN 53 Kubu Raya menyampaikan 80\% siswi kelas V merasa takut, cemas, bingung, dan malu saat ditanya mengenai menstruasi. Analisis penelitian ini menyebutkan bahwa kurangnya informasi yang didapat secara rinci dan kurangnya kesiapan anak dalam menghadapi menarche dipengaruhi oleh kurangnya informasi tentang menarche. 
Kesiapan mental sangatlah diperlukan, karena perasaan cemas dan takut akan muncul bila kurangnya pemahaman remaja putri tentang menarche. Untuk itu, remaja perlu persiapkan dalam menghadapi datangnya menarche (Sukarni \& Wahyu, 2013). Remaja dalam mempersiapkan datangnya menarche memerlukan dukungan, baik dukungan secara emosional, informasi, penghargaan dan instrumental. Dukungan tersebut dapat diperoleh dari lingkungan keluarga (orang tua), lingkungan sekolah (guru), lingkungan teman sebaya, dan lingkungan masyarakat (sosial budaya dan media massa). Lingkungan dalam keluarga merupakan lingkungan pertama dan utama bagi perkembangan anak (Aryani, 2010).

Orangtua dapat berperan aktif dalam memberikan pemahaman tentang menarche, karena ini merupakan hal yang sangat awal bagi seorang remaja. Dengan pemahaman tersebut, diharapkan remaja putri mengetahui upaya-upaya yang harus dilakukan jika mengalami menarche, sehingga mereka mampu melakukan perawatan dan personal hygiene seperti mengganti pembalut minimal dua kali sehari karena kebersihan organorgan reproduksi atau seksual merupakan awal dari usaha menjaga kesehatan genetalia (Proverawati \& Misaroh, 2009). Jika seorang remaja tidak diberikan pemahaman tentang menarche dan tidak dipersiapkan untuk menghadapi menarche akan timbul perasaan atau keinginan untuk menolak proses fisiologis tersebut, pada remaja terkadang akan timbul anggapan yang salah tentang menstruasi, mereka akan beranggapan menstruasi itu sesuatu yang kotor, tidak suci, najis dan ternoda. Terkadang mereka akan beranggapan akan mati karena banyak darah yang keluar dari vagina (Mansur \& Budiarti, 2014).

Orangtua sebaiknya meluangkan sedikit waktunya untuk anaknya karena orang tua mempunyai tanggung jawab dalam memberikan penjelasan atau informasi mengenahi menstruasi kepada anak perempuannya agar anak lebih mengerti dan siap menghadapi menarche (Mayangsari, 2015; Prasetyo et al., 2016). Hasil penelitian Nagar \& Aimol (2010) tentang pengetahuan remaja Meghalaya (India) tentang menstruasi menunjukan bahwa $50 \%$ pengetahuan tentang menstruasi diperoleh remaja dari teman, $36 \%$ pengetahuan tentang menstruasi diperoleh dari ibu dan 19\% diperoleh dari keluarga terdekat (Setyowati \& Purwati, 2015).

Pada masa remaja akan terjadi perkembangan psikologis pada remaja, secara emosional yang akan mempengaruhi psikologis remaja yang ingin lepas dari orangtua dan membentuk hubungan dan minat yang baru, yang ingin mencoba hal-hal yang baru. Salah satu peristiwa yang menyebabkan rasa ingin tahu remaja, khususnya perempuan adalah peritiwa menarche. Pada masa remaja labilnya emosi erat kaitannya dengan perubahan hormon dalam tubuh. Sering terjadi letusan emosi dalam bentuk amarah, sensitif, bahkan perbuatan nekad (Notoatmodjo, 2009).

Semua peristiwa tersebut biasa dihadapi secara normal pada anak gadis, tetapi kadang kala juga bisa berjalan tidak lancar atau tidak normal dikarenakan banyak hambatan dan dapat menimbulkan masalah-masalah psikosomatis (Suryani \& Widyasih, 2008). Sarwono (2008) mengatakan bahwa perubahan yang terjadi pada saat menarche menyebabkan remaja putri menjadi malu. Oleh karena itu remaja putri perlu mengadakan penyesuaian tingkah laku. Penyesuaian tersebut tidak dapat dilakukan dengan mulus, terutama jika tidak ada dukungan dari orangtua terutama ibu. Peran ibu sangat penting dalam proses pertumbuhan dan perkembangan anak, terutama pada saat masa remaja. Remaja mulai mengenal berbagai proses seksual yang sedang terjadi pada tubuh dan jiwanya pertama kali melalui ibu. 


\section{METODE PENELITIAN}

Jenis penelitian yang digunakan dalam penelitian ini adalah penelitian kuantitatif analitik, waktu pengumpulan data yang digunakan dalam penelitian ini adalah pendekatan cross sectional study. Teknik pengambilan sampel menggunakan total sampling dengan jumlah sampel 258 siswi. Data yang digunakan dalam penelitian ini adalah data primer diperoleh melalui kuesioner yang diisi langsung oleh responden yang disebarkan langsung oleh peneliti dan anggota peneliti, dan dilakukan pengolahan data meliputi editing, coding, cleaning, dan tabulating. Analisa data dilakukan secara univariat dan bivariat.

\section{HASIL PENELITIAN}

Tabel. 1

Distribusi Dukungan Ibu kepada Remaja Putri dalam Mengahadapi Menarche

\begin{tabular}{|c|c|c|c|}
\hline No & Dukungan ibu & Frekuensi & $\%$ \\
\hline 1 & Ada & 127 & 49,2 \\
\hline 2 & Tidak ada & 131 & 57,8 \\
\hline & Total & 258 & 100 \\
\hline
\end{tabular}

Berdasarkan tabel 1 diketahui bahwa mayoritas remaja putri tidak mendapatkan dukungan ibu dalam menghadapi menarche sebanyak 131 orang $(57,8 \%)$.

Tabel. 2

Distribusi Kesiapan Remaja Putri dalam Mengahadapi Menarche

\begin{tabular}{clccc}
\hline No & & Kecemasan & Frekuensi & $\%$ \\
\hline 1 & Siap & 148 & 57,4 \\
2 & Tidak & 110 & 42,6 \\
& Total & 258 & 100 \\
\hline
\end{tabular}

Berdasarkan table 2 dapat diketahui bahwa mayoritas remaja putri mengalami cemas dalam menghadapi menarce sebanyak 148 orang $(57,4 \%)$.

Table. 3

Hubungan Dukungan Ibu dengan Kesiapan Remaja Putri dalam Menghadapi Menarche

\begin{tabular}{|c|c|c|c|c|c|c|c|}
\hline \multirow{3}{*}{ Kesiapan } & \multicolumn{4}{|c|}{ Kecemasan } & \multirow{2}{*}{\multicolumn{2}{|c|}{ Total }} & \multirow[b]{2}{*}{$\mathrm{P}$ value } \\
\hline & \multirow{2}{*}{$\frac{\text { Cemas }}{\mathrm{N}}$} & \multicolumn{3}{|c|}{ Tidak } & & & \\
\hline & & $\%$ & $\mathrm{~N}$ & $\%$ & $\mathrm{~N}$ & $\%$ & \multirow{4}{*}{0,000} \\
\hline Tidak & 82 & 74,5 & 28 & 25,5 & 110 & 100 & \\
\hline Siap & 49 & 33,1 & 99 & 66,9 & 148 & 100 & \\
\hline Total & 131 & 50,8 & 127 & 49,2 & 258 & 100 & \\
\hline
\end{tabular}

Berdasarkan tabel 3 dapat diketahui bahwa sebagian besar remaja yang mendapat dukungan ibu dan siap menghadapi menarche sebanyak 99 orang $(66,9 \%)$ dari hasil chi-square diperoleh hasil $\mathrm{p}$ value $<0,05(0,000)$ artinya terdapat hubungan antara dukungan ibu dengan kesiapan remaja putri menghadapi menarche. 


\section{PEMBAHASAN}

Hasil penelitian menunjukkan bahwa terdapat hubungan antara dukungan ibu dengan kesiapan remaja putri menghadapi menarche. Mayoritas remaja putri mendapatkan dukungan dan siap menghadapi menarche sebanyak 99 orang.

Hasil penelitian didukung dengan penelitian Astuti (2015) menunjukkan bahwa didapatkan 37,4\% responden mendapat dukungan ibu dengan tingkat tinggi, salah satu faktor dukungan ibu yang baik adalah pendidikan, semakin baik tingkat pendidikan maka semakin baik pula pengetahuan yang didapat. Maka dapat disimpulkan bahwa dukungan ibu dan kesiapan remaja putri menghadapi menarche di Desa Sanur sudah cukup baik.

Penelitian ini sejalan dengan penelitian yang dilakukan oleh Salangka et al., (2018) yang menyatakan bahwa ada hubungan antara dukungan keluarga dengan kesiapan remaja putri dalam menghadapi menarche di SMP Negeri 1 Kawangkoan.

Penelitian ini juga sejalan dengan hasil penelitian yang dilakukan oleh (Nilawati, 2013) dengan judul hubungan dukungan ibu dangan kecemasan remaja dalam menghadapi menarche di Kabupaten Cilacap diketahui bahwa terdapat hubungan antara dukungan ibu dengan kecemasan remaja dalam menghadapi menarche. Penelitian ini juga sejalan dengan penelitian Aboyeji (2015) keluarga mempunyai peranan yang besar dalam memberikan informasi tentang perkembangan pada remaja, oleh karena itu keluarga diharapkan dapat memberikan dukungan emosi sehingga remaja merasa nyaman dan tidak takut untuk mengalami perkembangan terutama pada remaja putri yaitu dengan datangnya menstruasi pertama (menarche).

Penelitian yang dilakukan oleh Khoirini \& Utari (2017) menyatakan bahwa ada hubungan antara komunikasi interpersonal ibu dengan kesiapan anak perempuan menghadapi menarche di SD Negeri IV Wates Kulon Progo Yogyakarta. Komunikasi ibu dan anak yaitu proses pengiriman dan penerimaan pesan antara ibu dan anak yang berlangsung secara tatap muka dan dua arah (interpersonal) dan disertai adanya niat atau intens dari kedua belah pihak, dimana keduanya berperan sebagai pembicara dan pendengar secara bergantian sehingga menimbulkan efek tertentu berupa respon dan umpan balik segera (feedback) (Ramadhaniyati, 2014). Penelitian ini sesuai dengan penelitian Cicilia \& Nurdian (2009) didapatkan bahwa ada hubungan yang signifikan antara peran ibu sebagai pendidik remaja dengan kesiapan menghadapi menarche.

Aryani (2010) mengemukakan bahwa dengan memberikan informasi atau pemahaman yang benar, menyangkut kesehatan reproduksi, remaja akan lebih memahami perkembangan dan perubahan yang akan dialaminya dan siap menghadapi pubertas. Kesiapan tersebut akan membantu anak untuk menghadapi dan menerima perubahan secara wajar. Anak akan menyadari dan memahami bahwa perubahan fisik dan psikologis yang dialaminya adalah sesuatu yang normal bagi seorang wanita dan bukan merupakan kelainan atau penyimpangan sehingga meraka terhindar dari pengaruh hal negatif. Dengan demikian anak diharapkan akan melewati masa pubertas dengan lebih mantap.

Menarche sering dihayati sebagai suatu pengalaman traumatis dan akan menimbulkan reaksi psikologis yang lebih negatif pada anak perempuan yang belum siap menghadapi menstruasi, dimana anak tersebut memiliki gambaran fantasi yang sangat aneh bersamaan dengan kecemasan dan ketakutan yang tidak masuk akal, dapat juga disertai dengan perasaan bersalah atau berdosa, dimana semua hal tersebut dikaitkan dengan masalah perdarahan pada organ kelamin dan proses haidnya (Jayanti \& Purwanti, 2012). 
Pada remaja terkadang akan timbul anggapan yang salah tentang menstruasi, bahwa menstruasi itu adalah sesuatu yang kotor, tidak suci, najis dan ternoda. Dampak atau akibat yang ditimbulkan dari kurangnya komunikasi yang dilakukan antara ibu dan anak akan menyebabkan kurangnya informasi dan pengetahuan anak perempuan mengenai masalah kesehatan reproduksi khususnya menstruasi sehingga anak akan mengalami ketidaksiapan baik secara fisik maupun mental dalam menghadapi menarche (Ramadhaniyati, 2014).

Kecemasan sebagai akibat dari ketidaksiapan yang tidak segera diatasi, dapat menimbulkan rasa takut yang berlebihan dan berulang-ulang terhadap 4 menstuasi (Fitriani \& Rohman, 2016). Dampak dari perubahan psikologis mengakibatkan minimnya kemampuan remaja untuk menguasai dan mengontrol emosi. Kondisi ini membuat remaja putri menjadi kurang bertenaga, keengganan bekerja, bosan pada setiap kegiatan yang melibatkan perorangan, kurang bergairah melaksanakan tugastugas di sekolah yang menyebabkan tidak stabilnya prestasi remaja putri (Mansur, 2014). Terdapat beberapa faktor yang mempengaruhi kesiapan anak perempuan dalam menghadapi menarche yaitu pengetahuan, usia, maturitas dan peran orang terdekat yaitu orang tua khususnya ibu.

Komunikasi ibu dan anak merupakan proses pengiriman dan penerimaan pesan antara ibu dan anak yang berlangsung secara tatap muka dan dua arah (interpersonal) dan disertai adanya niat atau intens dari kedua belah pihak, dimana keduanya berperan sebagai pembicara dan pendengar secara bergantian sehingga menimbulkan efek tertentu berupa respon dan umpan balik segera (feedback) (Ramadhaniyati, 2014).

Terdapat banyak alasan mengapa remaja putri sering tidak dipersiapkan untuk menghadapi menstruasi pertama, misalnya orangtua yang kurang memiliki pengetahuan terhambat oleh rasa malu terhadap anak dan sopan santun. Sebagai orangtua seharusnya memberitahu anak perempuannya bahwa perdarahan selama menstruasi adalah normal yang dialami oleh semua anak perempuan dan membantu anaknya agar tidak terlalu cemas dalam menghadapi menstruasi pertama, mereka akan mengembangkan tingkah laku positif untuk menghadapi perubahan fisik dan psikologis (Leliana \& Wahyuni, 2010).

Ayed et al., (2016) mengidentifikasi beberapa hambatan yang dirasakan oleh para ibu dan anak perempuan untuk memulai sebuah komunikasi. Banyak ibu menyatakan bahwa mereka hanya memulai diskusi tentang topik kesehatan seksual dan reproduksi dengan putri mereka hanya pada kesempatan tertentu, seperti perubahan hidup atau suatu peristiwa, atau ketika anak perempuan mencari informasi tertentu atau meminta saran. Sedangkan anak perempuan melaporkan bahwa mereka enggan untuk meminta ibu mereka untuk jenis informasi karena malu, takut dihakimi, dan dirasakan kurangnya minat ibu mereka atau kemauan untuk memulai sebuah komunikasi, ketersediaan waktu, dan rasa percaya. Faktor penting yang membuat banyak gadis atau remaja enggan memulai diskusi adalah ketakutan bahwa ibu mereka akan curiga pada mereka dan mempertanyakan moral dan perilaku mereka.

Kesiapan remaja putri untuk menerima menarche tergantung beberapa hal, salah satunya dipengaruhi oleh faktor perilaku orang tua sebagian besar ibu tidak mengajari anak perempuan mereka tentang menstruasi, lama menstruasi, dan pemeliharaan kesehatan selama menstruasi. Dukungan yang diberikan ibu kepada remaja dapat mempengaruhi kecemasan, jika remaja yang tidak mendapatkan dukungan dari ibu mereka tidak siap untuk menerima menstruasi yang pertama. Kecemasan dapat terjadi pada remaja putri yang pertama kali mengalami mentruasi (menarche), karena 
ketidaktahuan dan adanya rasa nyeri yang dirasakan. Disamping itu, remaja juga merupakan masa peralihan dari masa kanak-kanak menuju masa dewasa, sehingga psikisnya juga dalam tahap perkembangan dan relatif tidak stabil. Sehingga remaja membutuhkan dukungan dari orang yang lebih dewasa dalam menghadapi hal-hal baru dalam hidupnya termasuk dalam menghadapi menarche (Soetjiningsih, 2010).

Faktor-faktor yang mempengaruhi kesiapan remaja dalam menghadapi menarche, antara lain faktor usia, sumber informasi yang berasal dari keluarga, kelompok teman sebaya atau lingkungan sekolah dan sikap (Hidayah \& Palila, 2015). Menurut Nastiti et al., (2013) kesiapan seorang perempuan dalam menghadapi menarche juga dipengaruhi oleh tingkat pengetahuan anak tentang menstruasi. Pengetahuan ini bisa didapatkan dari berbagai sumber informasi seperti keluarga, kelompok teman sebaya, lingkungan sekolah dan media baik cetak maupun elektronik. Informasi yang didapatkan di media cetak dan elektronik tidak dapat sepenuhnya dimengerti secara baik dan benar oleh anak karena pola pikirnya masih sederhana (Nanik et al., 2013). Namun jika mereka tidak mendapatkan di media, mereka akan saling bertanya kepada teman sebayanya yang sama belum paham mengenai menstruasi (Hurlock, 2004; Hidayah, 2015).

Kesiapan remaja putri dalam menghadapi menarche memerlukan dukungan dari orang tua, dukungan tersebut dapat berupa dukungan informasi, emosional, penghargaan, dan instrumental, seperti yang dikemukan oleh penelitian Putu (2013) kesiapan remaja putri dalam menghadapi menarche tergantung beberapa hal, salah satunya dipengaruhi oleh faktor perilaku orang tua, sebagian besar ibu tidak mengajari anak perempuan mereka tentang masalah menstruasi seperti usia mendapatkan menstruasi, lama menstruasi dan pemeliharaan kesehatan selama menstruasi.

Dukungan keluarga yang diberikan kepada remaja akan mempengaruhi kecemasan dan kesiapan remaja putri tersebut. Hal ini dikarenakan anggota keluarga merupakan orang yang paling dekat bagi remaja sehingga komunikasi pada halhal yang sensitif akan lebih terbuka. Keluarga berperan aktif dalam mengetahui kondisi remaja putri, baik fisik maupun psikologisnya karena keluarga bersifat saling ketergantungan satu anggota keluarga dengan anggota keluarga lainnya (Nainggolan \& Tambunan, 2013).

Dukungan keluarga sangat berpengaruh dalam kesiapan remaja putri menghadapi suatu keadaan yaitu dengan datangnya menstruasi. Bila anak tidak diberikan dukungan keluarga, baik dukungan informasi, emosional, penghargaan, dan instrumental akan berpengaruh terhadap kesiapan remaja putri tersebut dalam menghadapi menstruasi (Salangka et al., 2018).

\section{SIMPULAN}

Dari hasil penelitian tentang deskripsi faktor yang mempengaruhi kesiapan remaja putri dalam menghadapi menarche yaitu mayoritas tidak mendapat dukungan ibu. Mayoritas kesiapan remaja menghadapi menarche. Hasil bivariat terdapat hubungan antara dukungan ibu dengan kesiapan remaja dalam menghadapi menarche.

\section{SARAN \\ Orangtua}

Disarankan agar orangtua lebih sering berkomunikasi dengan anak dalam hal perkembangan pengetahuan menarche agar anak lebih membuka diri pada orangtua. 


\section{Peneliti Selanjutnya}

Untuk peneliti selanjutnya sebelum dilakukan penelitian, sebaiknya dilakukan uji validitas pada kuesioner agar hasil penelitian menjadi lebih baik, sebaiknya pada variabel confounding dikontrol agar risiko bias bisa dihentikan.

\section{DAFTAR PUSTAKA}

Aboyeji, A. (2015). Peran Ibu dalam Perubahan Psikologi Remaja Saat Mengalami Menarche. E-Journal Undip. http://www.ejournal.undip.ac.id/index.php/psikologi

Aryani, R. (2010). Kesehatan Remaja: Problem dan Solusinya. Jakarta: Salemba Medika

Astuti, N. (2015). Hubungan Dukungan Ibu dengan Kesiapan Remaja Putri Menghadapi Menarche di Desa Sanur. Universitas Udayana

Ayed, M. M. A., Thabet, A. M., Esia, E. E. E. R., \& Mostafa, N. E. H. (2016). Adolescent Girls Communication with Their Mothers on Sexual and Reproductive Health Matters among Secondary and Preparatory Schools Students, Journal of American Science, 12(7), 36-37

Cicilia. C., \& Nurdian, L. (2009). Hubungan Peran Ibu Sebagai Pendidik Remaja dengan Kesiapan Menghadapi Menarche pada Siswi Usia 10-12 tahun di SD Negeri 3 Sedayu Bantul Yogyakarta. STIKES 'Aisyiyah. Yogyakarta

Effendi, F., \& Makhfudli, M. (2009). Keperawatan Komunitas: Teori dan Praktik. Jakarta: Salemba

Fajri, A., \& Khairani, M. (2011). Hubungan antara Komunikasi Ibu-Anak dengan Kesiapan Menghadapi Menstruasi Pertama (Menarche) pada Siswi SMP Muhammadiyah Banda Aceh. Jurnal Psikologi Undip, 10(2), 133-143. http://www.ejournal.undip.ac.id/index.php/psikologi/article/view/2885

Fitriani, H., \& Rohman, R. Y. (2016). Pengaruh Konseling terhadap Kecemasan Remaja Putri yang Mengalami Menarche, Jurnal Ilmu Keperawatan, IV(2), 85-94. http://ejournal.bsi.ac.id/ejurnal/index.php/jk/article/view/859/705

Hidayah, N., \& Palila, S. (2015). Hubungan antara Kelekatan Aman terhadap Ibu dengan Kesiapan Remaja Putri Prapubertas Menghadapi Menstruasi Pertama (Menarche). Universitas Islam Negeri Sunan Kalijaga Yogyakarta

Hurlock, E. B. (2004). Psikologi Perkembangan: Suatu Pendekatan Sepanjang Rentang Kehidupan. Edisi Kelima. Jakarta: Erlangga

Jayanti, N. F., \& Purwanti, S. (2012). Deskripsi Faktor-Faktor yang Mempengaruhi Kesiapan Anak Dalam Menghadapi Menarche di SD Negeri 1 Kretek Kecamatan Paguyangan Kabupaten Brebes Tahun 2011. Jurnal Ilmiah Kebidanan, 3(1), 1-14. http://ojs.akbidylpp.ac.id/index.php/Prada/article/view/11/10

Khoirini, H., \& Utari, D. (2017). Hubungan Komunikasi Interpersonal Ibu dengan Kesiapan Anak Perempuan Menghadapi Menarche di SD Negeri IV Water Kulon Progo Yogyakarta. Sekolah Tinggi Ilmu Kesehatan Jenderal Achmad Yani Yogyakarta

Kusmiran, E. (2012). Kesehatan Reproduksi Remaja dan Wanita. Jakarta: Salemba Medika

Leliana, L., \& Wahyuni, A. (2010). Hubungan Pengetahuan Remaja Putri terhadap Kesiapan dalam Menghadapi Menarche di SD AL - Azhar Medan. Universitas Sumatera Utara

Mansur, H.,\& Budiarti, T. (2014). Psikologi Ibu dan Anak. Jakarta: Salemba Medika 
Mayangsari, D. N. (2015).Hubungan Dukungan Informasional Orangtua terhadap Kecemasan Anak Menghadapi Menarche di Dusun Rewulu Wetan. Universitas Muhammadiyah Yogyakarta

Munda, S. S., Wagey, W. F., \& Wantania J. (2013). Hubungan antara IMT dengan Usia Menarche pada Siswi SD dan SMP di Kota Manado. Jurnal Kesehatan Bagian Obstetri dan Ginekoli Universitas Sam Ratulangi., 1(1) http://ejournal.unsrat.ac.id/index.php/eclinic/article/viewFile/3289/2832.

Nagar, S, \& Aimol, R. (2010). Knowledge of Adolescent Girls Regarding Menstruation in Tribal Areas of Meghalaya. Journal Srudies of Tribes and Tribals, 8(1), 27-30. . https://doi.org/10.1080/0972639X.2010.11886610

Nainggolan, E., \& Tambunan, D. (2013). Tingkat Kecemasan Orangtua Menghadapi Perubahan Perilaku Remaja pada Masa Pubertas di Kelurahan Balige. Jurnal keperawatan HKBP Balige, 1(1), 82-84

Nanik, C., Winarni, S., \& Dharminto. (Hubungan Pemanfaatan Media Informasi dan Komunikasi Interpersonal oleh Ibu dengan Pengetahuan Remaja Awal tentang Pubertas pada Wanita di SDN Sudimara 13 Kota Tangerang. Jurnal Kesehatan Masyarakat Unversitas Diponegoro, 1-8. https://www.neliti.com/id/publications/18326/

Nastiti, F. D., Andayani, A., \& Diah, M. (2013). Hubungan Tingkat Pengetahuan Menarche dengan Kesiapan Siswi Kelas V dan VI Menghadapi Menarche di SD Negeri 1 Gedanganak. Menarche di SD Negeri 1 Gedanganak. Akademi Kebidanan Ngudi Waluyo

Nilawati, I. (2013). Hubungan Dukungan Ibu dangan Kecemasan Remaja dalam Menghadapi Menarche di Kabupaten Cilacap. Jurnal Ilmiah Kebidanan, 4, 178189

Notoatmodjo, S. (2009). Promosi Kesehatan Teori dan Aplikasi. Jakarta: Rineka Cipta

Prasetyo, M. G., Winarsih, N. A., \& Endang, Z. S. (2016). Hubungan Dukungan Orangtua dengan Kesiapan Anak Remaja Putri Menghadapi Menarche di SD Negeri Dukuh 01 Mojolaban Sukoharjo. Universitas Muhammadiyah Surakarta

Proverawati, A., \& Misaroh, S. (2009). Menarche Menstruasi Pertama Penuh Makna. Jakarta: Mulia Medika

Putu, A. (2013). Hubungan antara Peran Orangtua dalam Pendidikan Kesehatan Reproduksi Remaja dengan Kesiapan Remaja Menghadapi Menarche pada Siswi

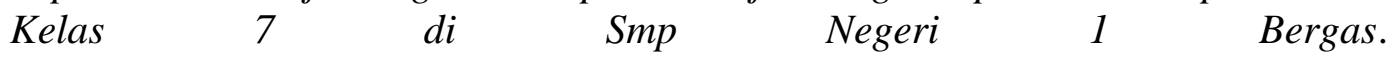
http://perpusnwu.web.id/karyailmiah/documents/3294.docx

Ramadhaniyati, R. (2014). Pengaruh Komunikasi Ibu tentang Menstruasi terhadap Kesiapan Anak Menghadapi Menarche pada Siswi Kelas V SD N 53 Kubu Raya tahun 2014, Jurnal Keperawatan dan Kesehatan, 5(3) 39-46. http://journal.stikmuhptk.ac.id/index.php/index/index

Salangka, G., Rompas, S., \& Regar M. (2018). Hubungan Dukungan Keluarga dengan Kesiapan Remaja Putri dalam Menghadapi Menarche di SMP Negeri 1 Kawangkoan. E-Journal Keperawatan (e-Kp), 6(1), 1-5

Santrock, J. W. (2010), Masa Perkembangan Anak. Jakarta: Salemba Humanika

Sarwono, S. W. (2008). Psikologi Remaja. Jakarta: PT: Raja Grafindo Persada

Setiowati, N., \& Purwati, Y. (2015). Hubungan Dukungan Ibu dengan Kesiapan menghadapi Menarche pada Siswi Kelas V dan VI MI Muhammadiyah Bonjor Tretep Temanggung. Sekolah Tinggi Ilmu Kesehatan 'Aisyiyah Yogyakarta 
Soetjiningsih. S. (2010). Tumbuh Kembang Remaja dan Permasalahnnya. Jakarta: Agung Seto

Solihah, I. A. (2013). Hubungan Pengetahuan tentang Menstruasi dengan Tingkat Kecemasan saat Menghadapi Menarche pada Siswi Kelas 1 di SMPN 1 Baleendah. Bandung. http://www.unigal.ac.id/ejurnal/download/22.pdf

Sukarni, I. K., \& Wahyu, P. (2013). Buku Ajar Keperawatan Maternitas. Yogyakarta: Nuha Medika

Suratmaja, D. H. (2013). 101 Tanya Jawab Seputar Seks. Klaten: Cable Book

Suryani, E., \& Widyasih, H. (2008). Psikologi Ibu dan Anak. Yogyakarta: Fitramaya

Trinuryati, D. (2014). Hubungan Dukungan Ibu dengan Kesiapan Anak Menghadapi Menarche di SD N Salam 1 Magelang. Sekolah Tinggi Ilmu Kesehatan Jendral Achmad Yani Yogyakarta, Yogyakarta 